Article

\title{
Combined Ball Milling and Ethanol Organosolv Pretreatment to Improve the Enzymatic Digestibility of Three Types of Herbaceous Biomass
}

\author{
Seong Ju Kim ${ }^{1}$, Byung Hwan Um ${ }^{2}$, Dong Joong $\mathrm{Im}^{3}$, Jin Hyung Lee ${ }^{4}$ and \\ Kyeong Keun $\mathrm{Oh}^{3,5, * \mathbb{D}}$ \\ 1 Department of Biomolecular and Chemical Engineering, Hankyong National University, Anseong, \\ Gyeonggi 17579, Korea; ksj1756@hknu.ac.kr \\ 2 Department of Chemical Engineering and Research Center of Chemical Technology, Hankyong National \\ University, Anseong, Gyeonggi 17579, Korea; bhum11@hknu.ac.kr \\ 3 R\&D Center, SugarEn Co., Ltd., Yongin, Gyeonggi 16890, Korea; Biol@daum.net \\ 4 Korea Institute of Ceramic Engineering and Technology, Jinju, Gyeongnam 52851, Korea; leejinh1@kicet.re.kr \\ 5 Department of Chemical Engineering, Dankook University, Yongin, Gyeonggi 16890, Korea \\ * Correspondence: kkoh@dankook.ac.kr; Tel.: +82-31-8005-3548
}

Received: 31 August 2018; Accepted: 14 September 2018; Published: 16 September 2018

\begin{abstract}
A combined ball milling and ethanol organosolv process is proposed for the pretreatment of three types of herbaceous biomass, giant miscanthus, corn stover, and wheat straw. The combined pretreatment was effective at both removing lignin and increasing the glucan content. After 120 min pretreatment, the glucan content increased to $63.09 \%$, and $55.89 \%$ of the acid-insoluble lignin was removed from the giant miscanthus sample. The removal of cellulose, hemicellulose, and acetyl groups were correlated with the removal of lignin. The pretreatment of corn stover showed the highest removal of cellulose, but this was dependent on the removal of acid-insoluble lignin. The slope of the regression lines, which shows the correlation between the removal of lignin and cellulose, was lower than other correlations. The changes in biomass size were analyzed using size distribution graphs. With increasing pretreatment time, the particle size reduction improved in the three types of herbaceous biomass. Because of the combined physicochemical pretreatment, the enzymatic digestibility improved, and a maximum of $91 \%$ glucan digestibility was obtained from the pretreated corn stover when $30 \mathrm{FPU} / g$-glucan enzyme was added. Finally, compositional analysis of the recovered lignin from the remaining black liquor was investigated.
\end{abstract}

Keywords: combined pretreatment; ball mill; ethanol organosolv; herbaceous biomass; lignin recovery

\section{Introduction}

Sugars derived from herbaceous biomass are important platform chemicals and can be further converted to high-value-added chemicals and biofuels via thermochemical or biological routes [1,2]. Pretreatment is an essential step in producing sugars from herbaceous biomass. Pretreatment reduces the amount of the structural polymer lignin, as well as the crystalline cellulose structure, thus increasing the accessibility of enzymes to the holocellulose [3,4]. Recently, lignin has emerged as a renewable source of aromatics for the chemical industry [5]. Therefore, both carbohydrate and lignin fractionation should be considered when pretreatment steps are applied to herbaceous biomass.

Pretreatment consists of biological, chemical, or physical processes [6,7]. Recently, combined physical and chemical pretreatment processes have been proposed to enhance enzymatic 
hydrolysis [8-12]. These combined methods increase enzymatic accessibility and reduce energy consumption [13].

Ball milling is one physical pretreatment method. Previous studies have reported that ball milling increases the accessible surface area and pore size and reduces the crystallinity and the polymerization degree of cellulose [14-17]. Because chemical catalysts are not used, there is no significant change in the chemical composition [18]. As a chemical pretreatment approach, organosolv is a promising method for the alcoholysis of lignin from herbaceous biomass [19]. This pretreatment employs organic solvents, mainly alcohols, or their aqueous solutions, which can be later reused and recovered [20,21]. The advantage of using organosolv is that highly pure lignin is obtained as a solid from the liquid phase; this can be used for high-value products such as adhesives, fibers, and biodegradable polymers $[20,22]$ or thermal fuel [23]. During the organosolv process, cellulose is recovered as a solid phase, whereas most of the lignin and partial hemicellulose is dissolved in the organic solvent as a liquid phase. The recovered solid, rich in cellulose, is readily hydrolyzed by enzymatic digestion because the lignin or hemicellulose has been removed, and this material can be used for further processing [24-27]. Finally, the fractionation of lignin and partial hemicellulose reduces the recalcitrance of the material to digestion and increases the accessibility of the material to enzymes, thereby enhancing enzymatic digestibility [28]. However, the two-stage pretreatment (physical and chemical) requires considerable energy, as well as additional reactors. Previous studies have reported that pretreatment combined with mechanical size reduction is effective in reducing the energy consumption in biorefinery plants [14,29-33].

In this study, we propose a novel pretreatment process where ball mill grinding and the ethanol-based organosolv process are conducted simultaneously. In this process, ball milling is used as a physical treatment to reduce the biomass size and improve enzymatic accessibility. Ethanol organosolv was used as a chemical treatment to fractionate the lignin, the major obstacle to cellulose digestion. In this study, the effects of the combined physicochemical pretreatment on fermentable sugar production were investigated using three types of herbaceous biomass.

\section{Materials and Methods}

\subsection{Raw Materials}

Three herbaceous biomasses namely, giant miscanthus (GM), corn stover (CS), and wheat straw (WS) were supplied by the Rural Development Administration (Wanju, Republic of Korea). The samples were air dried at room temperature and used directly in the pretreatment processes. The moisture contents of GM, CS, and WS were $2.92 \%, 3.08 \%$, and $3.20 \%$, based on the total wet biomass weight, respectively. The chemical compositions of the raw materials are shown in Table 1.

Table 1. Compositions of the three types of herbaceous biomass used in this study. GM: Giant Miscanthus; CS: corn stover; WS: wheat straw.

\begin{tabular}{ccccc}
\hline \multicolumn{2}{c}{ Compositions (\%) } & GM & CS & WS \\
\hline \multirow{5}{*}{ Carbohydrates } & Glucan & $43.77 \pm 0.07$ & $30.30 \pm 0.26$ & $31.42 \pm 0.44$ \\
& Xylan & $21.22 \pm 0.08$ & $16.58 \pm 0.19$ & $21.38 \pm 0.09$ \\
& Mannan & - & $0.60 \pm 0.21$ & - \\
& Galactan & - & $1.53 \pm 0.47$ & $1.56 \pm 0.14$ \\
& Arabinan & $0.50 \pm 0.01$ & $0.82 \pm 0.02$ & $1.00 \pm 0.02$ \\
& Sub Total & 65.49 & 49.83 & 55.36 \\
\hline \multirow{3}{*}{ Lignin } & Acid soluble & $0.96 \pm 0.01$ & $1.47 \pm 0.03$ & $1.11 \pm 0.02$ \\
& Acid insoluble & $19.55 \pm 0.01$ & $12.38 \pm 0.09$ & $13.47 \pm 0.24$ \\
& Sub Total & 20.51 & 13.85 & 14.58 \\
\hline \multirow{3}{*}{ Extractive } & Water & $4.96 \pm 0.71$ & $21.14 \pm 0.12$ & $17.11 \pm 0.33$ \\
& Ethanol & $1.47 \pm 0.11$ & $3.71 \pm 0.22$ & $2.77 \pm 0.27$ \\
& Sub Total & 6.43 & 24.85 & 19.88 \\
\hline \multicolumn{2}{c}{ Acetyl group } & $3.88 \pm 0.02$ & $2.76 \pm 0.06$ & $3.02 \pm 0.06$ \\
\hline & Ash & $2.18 \pm 0.03$ & $7.92 \pm 0.05$ & $7.36 \pm 0.10$ \\
\hline
\end{tabular}




\subsection{Combined Physicochemical Pretreatment}

The combined ball milling and ethanol organosolv pretreatment was performed in a rotary-pressured type reactor (Hanul Engineering Co., Gunpo, Korea). For the pretreatment, $370 \mathrm{~g}$ of dried herbaceous biomass and $11 \mathrm{~kg}$ of alumina balls $(\varnothing=10 \mathrm{~mm})$ were added to the reactor with $3.7 \mathrm{~L}$ of $60 \%(v / v)$ ethanol solution $(1: 10: 30(w / v / w)$ for biomass, solvent, and ball, respectively). The rotary-pressure-type reactor was kept at $170{ }^{\circ} \mathrm{C}$ for $30-120 \mathrm{~min}$ and rotated at $50 \mathrm{rpm}$. After reaction, it was cooled to $80^{\circ} \mathrm{C}$, and the mixture was separated into solid biomass, lignin-containing liquid, and alumina balls. The treated solid biomass was washed with distilled water and stored until use. After pretreatment, the particle size distribution of the pretreated biomass was determined by the shaking sieve method after drying at $45{ }^{\circ} \mathrm{C}$ overnight. The sieves used were US sieve numbers 6 , $14,20,40,80,170$, and 270 (sieve opening sizes: 3.35, 1.4, 0.85, 0.425, 0.180, 0.09, and $0.053 \mathrm{~mm}$, respectively). Lignin was recovered from the remaining black liquor by 3 -fold dilution with distilled water. After $24 \mathrm{~h}$, the precipitated lignin was collected by filtration.

\subsection{Enzymatic Digestibility}

Enzymatic digestibility was analyzed according to the National Renewable Energy Laboratory (NREL) standard procedures [34]. A commercial cellulase (Cellic CTec 2, Novozymes Korea Ltd., Seoul, Korea) was used. The enzyme hydrolysis was performed at $50{ }^{\circ} \mathrm{C}$ and $\mathrm{pH} 4.8(50 \mathrm{mM}$ sodium citrate buffer) while the solution was shaken at $150 \mathrm{rpm}$. The quantity of cellulase loaded was 15 or $30 \mathrm{FPU}$ (filter paper unit)/g-glucan. Experiments were conducted in 250-mL Erlenmeyer flasks with a total working volume of $100 \mathrm{~mL}$, and the glucan concentration was maintained at $1.0 \%(w / v)$. Samples were taken periodically $(0,3,6,9,12,24,48,72$, and $96 \mathrm{~h})$ and boiled for $5 \mathrm{~min}$ to deactivate the enzymes, followed by filtration through a $0.45 \mu \mathrm{m}$ nylon membrane filter for glucose content analysis using a high-performance liquid chromatography (HPLC) column (Bio-Rad Laboratories, Hercules, CA, USA). All experiments were performed in triplicate for error analysis. Finally, the glucan digestibility was calculated using Equation (1).

$$
\text { Lignin removal percentage }(\%)=100-m_{\operatorname{Re}} / m_{\mathrm{L}} \times 100
$$

where $m_{\text {Re }}$ refers to the dry weight mass of remaining lignin after composition analysis of solid residues and $m_{\mathrm{L}}$ represents the mass weight of lignin in the original loaded biomass $\left(m_{\mathrm{L}}=\right.$ the loaded biomass mass weight $\times$ the lignin content) [35].

\subsection{Compositional Analysis of the Solid and Liquid Phases}

The compositions of the solid and liquid samples were determined according to analytical procedures of the NREL (NREL/TP-510-42623 for structural carbohydrates and lignins; NREL/TP-510-42618 for sugars in the liquids or in the hydrolyzates) [36,37]. The sugars were determined using a HPLC (Agilent 1260 Infinity, Agilent Technologies, Santa Clara, CA, USA) equipped with a refractive index detector (Agilent 1260 Infinity, Agilent Technologies, Santa Clara, CA, USA). A Bio-Rad Aminex HPX-87H column (300 mm length $\times 7.8 \mathrm{~mm}$ internal diameter) and a Cation $\mathrm{H}$ micro-guard cartridge ( $30 \mathrm{~mm}$ length $\times 4.6 \mathrm{~mm}$ internal diameter, Bio-Rad Laboratories Inc., Hercules, CA, USA) were used for sugar, organic acid, and decomposition product analysis. The samples were filtered using syringe filters having a $0.45-\mu \mathrm{m}$ pore size before analysis, and $5 \mathrm{mM}$ sulfuric acid was used as the mobile phase. The temperature of the column was set at $65^{\circ} \mathrm{C}$ and the flow rate of the mobile phase was $0.5 \mathrm{~mL} / \mathrm{min}$. The remaining solid was filtered, dried, and burned in a muffle furnace at $575{ }^{\circ} \mathrm{C}$ for lignin analysis. The ash content of the samples was determined by complete combustion in a muffle furnace (DMF12, Romax, Co., Seoul, Korea) equipped with a temperature controller and by running a temperature ramp program according to the NREL/TP-510-42622 method. The remaining residue in the crucible was taken as the ash content [38]. The compositional analysis was performed in triplicate. 


\section{Results}

\subsection{Compositions of Herbaceous Biomasses Used in This Study}

The compositions of the herbaceous biomass samples used in this study are presented in Table 1. GM had the highest carbohydrate and lignin content among the three types of herbaceous biomass: 43.8\% glucan, $21.22 \%$ xylan, mannan, and galactan (XMG), and $20.51 \%$ lignin (acid soluble + acid insoluble). In contrast, CS and Wheat straw (WS) contained approximately 50\% carbohydrates and $14 \%$ lignin. However, the extractive content of GM was much lower than those of CS and WS. The differences in biomass composition could be due to the characteristics of each herbaceous biomass source. These differences in composition result in unique physical/chemical properties. Therefore, it is important to find the optimum pretreatment conditions that are tailored to the properties of each biomass type.

\subsection{Composition Changes after Combined Physicochemical Pretreatment}

The goals of pretreatment are to reduce the lignin content to improve the accessibility of the enzyme and to increase the glucan and XMG content. Wanting to optimize the combined physicochemical pretreatment conditions, we investigated the conditions where lignin removal was maximal while the cellulose content was maintained.

Table 2 presents the compositional changes with increasing reaction time of the GM sample after pretreatment. The combined pretreatment by ball mill and ethanol organosolv was effective in both removing acid-insoluble lignin (AIL) and increasing glucan content in GM (Table 2). With increasing reaction time, the glucan content increased to $63.09 \%$ after 120 min reaction. Removal of acid-insoluble lignin increased with reaction time. The XMG contents decreased when the reaction time increased from 90 to $120 \mathrm{~min}$ (Table 2), and the acetyl group contents also decreased. However, the AIL content did not decrease but the glucan content increased by about $6 \%$ when the remaining solid is considered.

Table 2. Changes in composition of giant miscanthus after the combined ball mill and organosolv pretreatment performed at $170{ }^{\circ} \mathrm{C}$ at $50 \mathrm{rpm}$ rotation. XMG: xylan, mannan, and galactan; AIL: acid-insoluble lignin.

\begin{tabular}{ccccccc}
\hline $\begin{array}{c}\text { Time } \\
(\mathbf{m i n})\end{array}$ & $\begin{array}{c}\text { Solid Remaining } \\
\mathbf{( \% )}\end{array}$ & $\begin{array}{c}\text { Glucan } \\
\mathbf{( \% )}\end{array}$ & $\begin{array}{c}\text { XMG } \\
\mathbf{( \% )}\end{array}$ & $\begin{array}{c}\text { Acetyl Group } \\
\mathbf{( \% )}\end{array}$ & $\begin{array}{c}\text { AIL } \\
\mathbf{( \% )}\end{array}$ & $\begin{array}{c}\text { AIL Removal } \\
\text { Percentage (\%) }\end{array}$ \\
\cline { 1 - 5 } Initial & $\mathbf{1 0 0}$ & $\mathbf{4 3 . 7 7}$ & $\mathbf{2 1 . 2 2}$ & $\mathbf{3 . 8 8}$ & $\mathbf{1 9 . 5 3}$ & \\
\hline 30 & 79.25 & 50.01 & 23.03 & 3.73 & 16.28 & 33.95 \\
60 & 72.29 & 52.22 & 21.79 & 3.36 & 15.89 & 41.18 \\
90 & 65.41 & 56.90 & 20.72 & 3.04 & 14.30 & 52.11 \\
120 & 57.44 & 63.09 & 15.14 & 2.10 & 15.00 & 55.89 \\
\hline
\end{tabular}

Table 3 presents the changes in the composition of corn stover before and after the combined physicochemical pretreatment with increasing reaction time. The AIL removal yield of corn stover linearly increased to $52.04 \%$ during $90 \mathrm{~min}$ reaction. The acetyl group content continuously decreased from $2.76 \%$ to $1.65 \%$ and glucan content steadily increased over 120 min reaction. However, the XMG content changed from $23.89 \%$ to $22.08 \%$ from 30 to 90 min of reaction time, respectively. The reason for this change could be the removal of extractives by ethanol. As shown for giant miscanthus, the AIL removal slightly increased to $53.91 \%$ after $120 \mathrm{~min}$ reaction when compared to that after 90 min reaction. 
Table 3. Change in composition of corn stover after the combined ball mill and organosolv pretreatment performed at $170{ }^{\circ} \mathrm{C}$ with $50 \mathrm{rpm}$ rotation.

\begin{tabular}{ccccccc}
\hline $\begin{array}{c}\text { Time } \\
(\mathbf{m i n})\end{array}$ & $\begin{array}{c}\text { Solid Remaining } \\
\mathbf{( \% )}\end{array}$ & $\begin{array}{c}\text { Glucan } \\
\mathbf{( \% )}\end{array}$ & $\begin{array}{c}\text { XMG } \\
\mathbf{( \% )}\end{array}$ & $\begin{array}{c}\text { Acetyl Group } \\
\mathbf{( \% )}\end{array}$ & $\begin{array}{c}\text { AIL } \\
\mathbf{( \% )}\end{array}$ & $\begin{array}{c}\text { AIL Removal } \\
\text { Percentage (\%) }\end{array}$ \\
\cline { 1 - 5 } Initial & $\mathbf{1 0 0}$ & $\mathbf{3 0 . 3 0}$ & $\mathbf{1 8 . 7 1}$ & $\mathbf{2 . 7 6}$ & $\mathbf{1 2 . 2 3}$ & \\
\hline 30 & 56.98 & 46.51 & 23.89 & 2.62 & 14.61 & 31.92 \\
60 & 48.32 & 48.58 & 22.91 & 2.18 & 14.97 & 40.84 \\
90 & 42.24 & 51.73 & 22.08 & 1.93 & 13.89 & 52.04 \\
120 & 39.28 & 53.16 & 20.27 & 1.65 & 14.35 & 53.91 \\
\hline
\end{tabular}

Table 4 shows the compositional changes of wheat straw. The removal percentage of AIL reached $48.39 \%$ after $120 \mathrm{~min}$, which is less than those of GM and CS. Like the other biomass types, the XMG and acetyl group contents steadily decreased but the glucan content increased with reaction time, up to $120 \mathrm{~min}$. The AIL content did not seem to change significantly. However, considering the relative content in the remaining solid, the AIL content was greatly decreased.

Table 4. Change in composition of wheat straw after the combined ball mill and organosolv pretreatment performed at $170{ }^{\circ} \mathrm{C}$ with $50 \mathrm{rpm}$ rotation.

\begin{tabular}{ccccccc}
\hline $\begin{array}{c}\text { Time } \\
(\mathbf{m i n})\end{array}$ & $\begin{array}{c}\text { Solid Remaining } \\
\mathbf{( \% )}\end{array}$ & $\begin{array}{c}\text { Glucan } \\
\mathbf{( \% )}\end{array}$ & $\begin{array}{c}\text { XMG } \\
\mathbf{( \% )}\end{array}$ & $\begin{array}{c}\text { Acetyl Group } \\
\mathbf{( \% )}\end{array}$ & $\begin{array}{c}\text { AIL } \\
\mathbf{( \% )}\end{array}$ & $\begin{array}{c}\text { AIL Removal } \\
\text { Percentage (\%) }\end{array}$ \\
\cline { 1 - 5 } Initial & $\mathbf{1 0 0}$ & $\mathbf{3 1 . 4 2}$ & $\mathbf{2 2 . 9 4}$ & $\mathbf{3 . 0 2}$ & $\mathbf{1 4 . 6 1}$ & \\
\hline 30 & 64.47 & 41.36 & 27.83 & 2.61 & 14.53 & 35.90 \\
60 & 58.07 & 44.93 & 26.76 & 2.45 & 15.19 & 39.62 \\
90 & 52.06 & 48.78 & 24.13 & 2.29 & 15.55 & 44.58 \\
120 & 50.70 & 50.15 & 22.71 & 1.97 & 14.87 & 48.39 \\
\hline
\end{tabular}

In previous studies, the pretreatment of lignocellulosic biomasses was carried out using acidic catalysts. El Hage et al. obtained 62\% AIL removal of Miscanthus samples when using 44\% EtOH with $0.5 \% \mathrm{H}_{2} \mathrm{SO}_{4}$ catalyst [39]. Huijgen et al. removed lignin from wheat straw using an acid catalyst and obtained a 56\% removal yield [40]. However, using an acid catalyst caused the dissolution of glucan into the liquid, and the acidic solution corroded the pretreatment equipment. In contrast, the combined physicochemical pretreatment used in this study did not cause a loss of glucan and showed good lignin removal yields.

After 30 min reaction time, of the three herbaceous biomass types, the highest percentage of remaining solid was found for GM. The percentages of remaining solid were $79.25 \%, 56.98 \%$, and $64.47 \%$ for GM., CS, and WS, respectively. The remaining solid could be related to the extractive content. The extractive contents (water + ethanol) were $6.43 \%, 24.85 \%$, and $19.88 \%$ for GM, CS, and WS, respectively, after $30 \mathrm{~min}$ pretreatment. The extractives were drawn into the liquid by ethanol during the combined physicochemical pretreatment. The remaining solid further decreased with reaction time, and the lowest value was $39.28 \%$ in the case of CS because it had the highest extractive content and, thus, underwent the highest removal of the main components.

\subsection{Correlation of Lignin Removal with the Removal of Other Compounds}

Using the combined physicochemical pretreatment, lignin was mostly removed, and cellulose/hemicellulose were partially removed. The robustness (or recalcitrance) of the lignocellulosic biomass is attributable to the crosslinking between the polysaccharides (cellulose and hemicellulose) and lignin via ester and ether linkages [41]. During the combined physicochemical pretreatment, the polysaccharides were first disconnected from lignin. The newly freed celluloses became dissolved in the ethanol and were broken down into monosaccharides. Simultaneously, lignin and hemicellulose were concurrently fractionated. The correlation between lignin removal 
with the removal of the various components is presented in Figure 1. It was found that the removal of cellulose, hemicellulose, and acetyl groups is correlated with lignin removal. As shown by the regression lines in Figure 1a, the dissolution of cellulose into the liquor occurred simultaneously with the removal of AIL. With increasing AIL removal, the cellulose dissolution also increased. The regression line for CS has a different slope compared to those of the other herbaceous biomass samples (Figure 1). CS showed higher removal of cellulose depending on the removal of AIL. For example, the percentages of removed cellulose were $66 \%, 35 \%$, and $29 \%$ for CS, WS, and GM, respectively, at the 100\% AIL removal point on the regression lines (Figure 1a). The correlation between lignin removal and hemicellulose removal is different from the correlation between the removal of lignin and cellulose. The slopes of the regression lines, which show the correlation between the removal of lignin and hemicellulose, is higher than that of lignin and cellulose because the hemicellulose is more easily removed because of the weak and amorphous structure. From our results, we determined that hemicellulose was rapidly removed when the AIL was dissolved during the combined ball milling and organosolv pretreatment. The correlation between the removal of lignin and acetyl groups also showed a similar pattern to that of hemicellulose. The cleavage of acetyl groups occurred rapidly, and the acetyl groups were also removed when AIL was removed (Figure 1c). Using the combined physicochemical pretreatment, the removal of crosslinking between lignin and the other compounds (cellulose, hemicellulose, and acetyl group) occurred initially. Subsequently, the components were dissolved and removed. However, complete AIL removal was difficult because of the strong crosslinks between the polysaccharides and lignin.
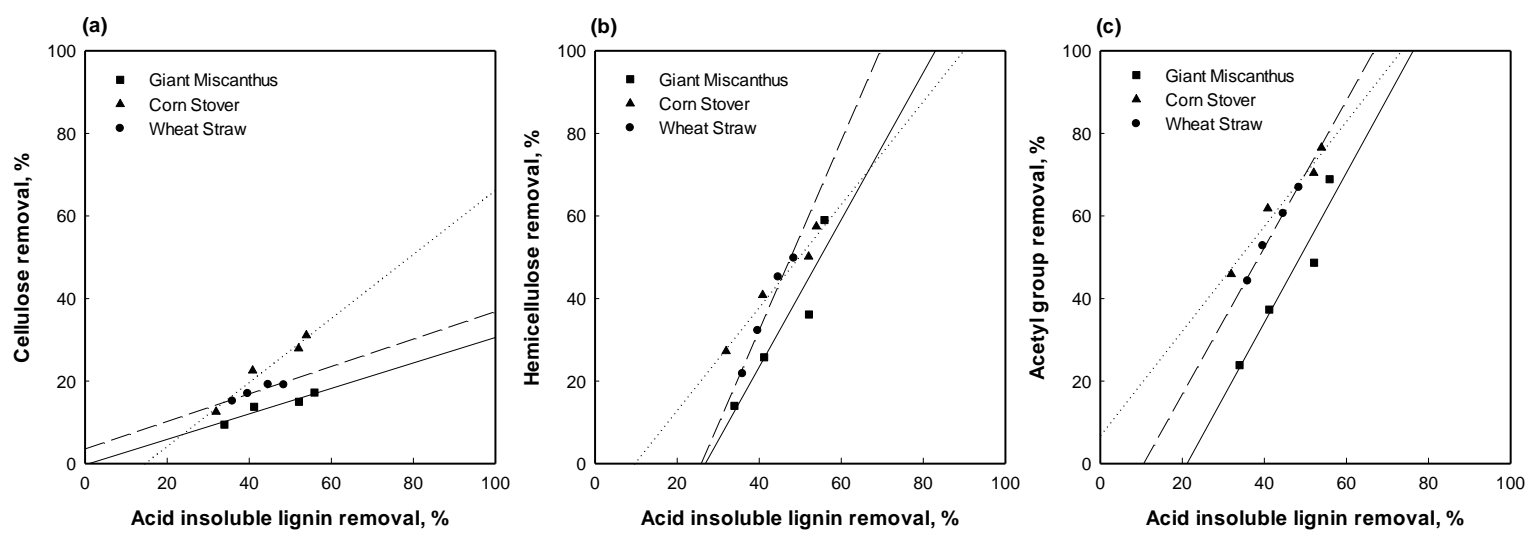

Figure 1. Correlation between the removal of lignin and other compounds: (a) cellulose; (b) hemicellulose; and (c) acetyl group by the combined physicochemical pretreatment.

\subsection{Changes in Biomass Particle Size}

The change in the size of the biomass particles with pretreatment time was investigated and expressed by calculating the number of particles that passed through sieves of different mesh sizes. All untreated herbaceous biomass samples showed positive skewness (Figure 2). With increasing pretreatment time, the size distribution curves became negatively skewed. The particle sizes after 30 and 60 min pretreatment did not significantly change when compared to those of the untreated samples (data not shown). However, significant changes to the size distribution curves were found after 90 min pretreatment time. Many untreated GM particles were collected after sieving through a 20-mesh sieve. With increasing pretreatment time, the relative amount of GM increased between the 40- and 170-mesh sieves. After 120 min pretreatment, a significant increase was found for the 40-mesh and 170-mesh sieves, indicating that the GM particles had become finer. Figure $2 \mathrm{~b}$ shows that the relative amount of CS particles passing through the 80 -mesh sieve drastically increased from $0.02 \%$ to $0.4 \%$ after $120 \mathrm{~min}$ pretreatment. Meanwhile, the relative number of CS particles larger than 20 mesh was reduced by the pretreatment. Similar results were also found for WS (Figure 2c). In this study, the ball milling process ground the biomass because of the friction between the ball and the biomass. 
Based on our results, ball milling was effective in pretreating the three types of herbaceous biomass used in this study.
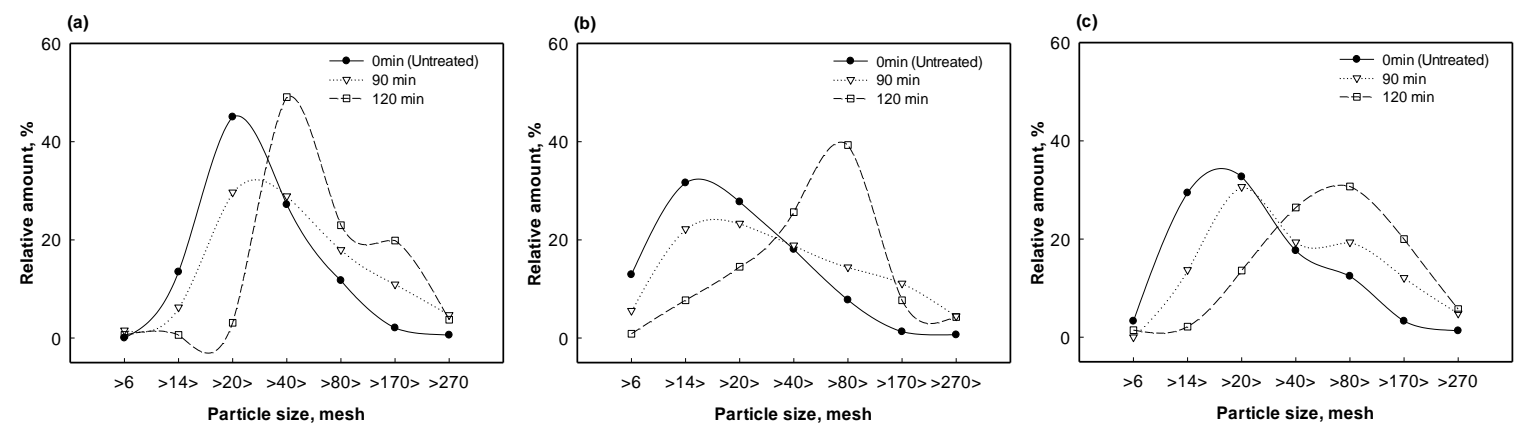

Figure 2. Biomass particle size distributions before and after the combined physicochemical pretreatment at different reaction times: (a) GM; (b) CS; and (c) WS.

\subsection{Enzymatic Digestibility of Pretreated Herbaceous Biomasses}

To evaluate the effect of pretreatment on cellulose accessibility, the enzyme digestibility was compared before and after the combined physicochemical pretreatment. Untreated GM showed very low glucan digestibility, less than $10 \%$. Even when the enzyme dosage was doubled, the glucose production did not increase significantly. However, the combined physicochemical pretreatment significantly improved the glucan digestibility. For the pretreated samples, a five-fold increase in glucan digestibility was obtained compared to that of the untreated sample (Figure 3a). In addition, the glucan digestibility increased with increasing enzyme dosage. Untreated CS showed relatively higher glucan digestibility than the other two types of herbaceous biomass. However, the glucan digestibility drastically increased after the combined physicochemical pretreatment. Specifically, treated CS showed 91\% glucan digestibility when the enzyme dose was $30 \mathrm{FPU} / \mathrm{g}$-glucan (Figure 3b). Untreated WS showed less than $20 \%$ glucan digestibility, even after the addition of $30 \mathrm{FPU} / \mathrm{g}$-glucan (Figure 3c). The treated WS showed 79\% and $88 \%$ glucan digestibility for enzyme doses of 15 and $30 \mathrm{FPU} / \mathrm{g}$-glucan, respectively, as shown in Figure 3c. These results indicate that the combined physicochemical pretreatment used in this study increased the cellulose surface area available for reaction with cellulase, improving enzyme accessibility.
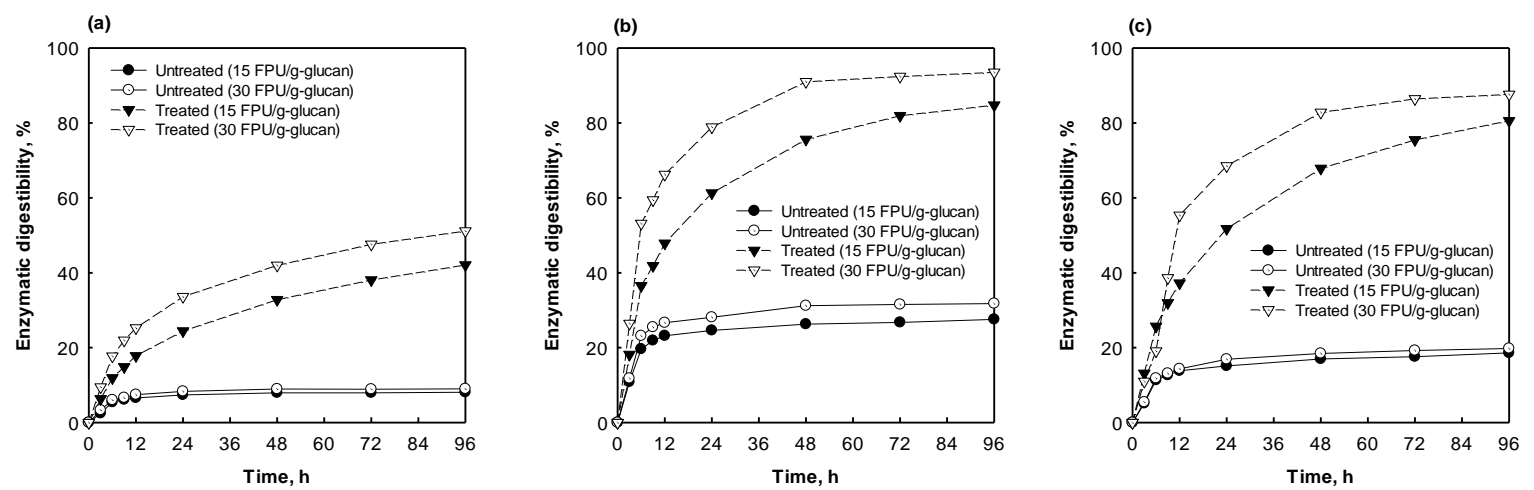

Figure 3. Glucan digestibility before and after pretreatment depending on enzyme dosage: (a) GM; (b) CS; and (c) WS.

\subsection{Composition of Recovered Lignin from the Black Liquor}

Lignin is byproduct in this process, but it is a very useful compound having biopolymer applications [42]. With increasing pretreatment time from 30 to $120 \mathrm{~min}$ in GM, the recovered lignin (AIL and acid-soluble lignin (ASL)) increased from $57.61 \%$ to $80.26 \%$ (Table 5). In contrast, the contents of glucan and XMG decreased. The contents of recovered lignin were $71.29 \%$ and $64.86 \%$ for CS 
and WS, respectively, after 120 min pretreatment. With increasing pretreatment time, the quantity of recovered lignin increased significantly for GM but increased only slightly for CS and WS.

Table 5. Composition of lignin obtained from the black liquor depending on pretreatment time. ASL: acid-soluble lignin; AIA: acid-insoluble ash.

\begin{tabular}{cccccccc}
\hline Biomass & Time (min) & AIL (\%) & ASL (\%) & AIA (\%) & Glucan (\%) & XMG (\%) & Acetyl Group (\%) \\
\hline \multirow{4}{*}{ GM } & 30 & 55.62 & 1.99 & 5.39 & 14.57 & 12.60 & 2.59 \\
& 60 & 59.02 & 1.85 & 5.41 & 10.74 & 13.00 & 2.65 \\
& 90 & 62.27 & 2.06 & 6.57 & 11.34 & 13.96 & 2.71 \\
& 120 & 77.94 & 2.32 & 1.58 & 2.66 & 11.87 & 2.73 \\
\hline \multirow{4}{*}{ CS } & 30 & 59.37 & 3.07 & 2.90 & 5.83 & 5.56 & 1.14 \\
& 60 & 64.28 & 3.29 & 2.34 & 5.76 & 6.23 & 1.37 \\
& 90 & 56.34 & 3.78 & 2.32 & 6.14 & 7.28 & 1.42 \\
& 120 & 67.81 & 3.48 & 2.39 & 4.68 & 6.28 & 1.24 \\
\hline \multirow{6}{*}{ WS } & 30 & 50.91 & 3.65 & 2.97 & 10.47 & 12.24 & 1.93 \\
& 60 & 54.42 & 2.78 & 4.30 & 10.10 & 11.44 & 1.69 \\
& 90 & 55.38 & 3.03 & 3.22 & 8.16 & 12.97 & 1.97 \\
\hline
\end{tabular}

\section{Conclusions}

A combined ball milling and ethanol organosolv pretreatment was effective in both increasing the glucan content and removing the acid-insoluble lignin. With increasing pretreatment time, the glucan content and lignin recovery were improved in all three types of herbaceous biomass. Lignin removal was correlated with the removal of cellulose, hemicellulose, and acetyl groups but the slope of the plot of cellulose removal to lignin removal was lower than those of the others. In summary, the combined pretreatment significantly improved the enzyme digestibility of all herbaceous biomass samples tested in this study.

Author Contributions: S.J.K., B.H.U., D.J.I., J.H.L., and K.K.O. contributed equally to this work. S.J.K. and D.J.I. contributed to the experimental process for combined fractionation process. B.H.U. and K.K.O. contributed to the project administration and experimental design. In addition, J.H.L. contributed to providing methodology and data validation. All the authors contributed to the writing and review of this document.

Funding: This work was funded by a grant the Korea Institute of Energy Technology Evaluation and Planning (KETEP) (Grant No. 2015010091990).

Conflicts of Interest: The authors declare no conflict of interest.

\section{References}

1. Wettstein, S.G.; Alonso, D.M.; Gürbüz, E.I.; Dumesic, J.A. A roadmap for conversion of lignocellulosic biomass to chemicals and fuels. Curr. Opin. Chem. Eng. 2012, 1, 218-224. [CrossRef]

2. Sheldon, R.A. Green and sustainable manufacture of chemicals from biomass: State of the art. Green Chem. 2014, 16, 950-963. [CrossRef]

3. Sun, Y.; Cheng, J. Hydrolysis of lignocellulosic materials for ethanol production: A review. Bioresour. Technol. 2002, 83, 1-11. [CrossRef]

4. Kumar, P.; Barrett, D.M.; Delwiche, M.J.; Stroeve, P. Methods for pretreatment of lignocellulosic biomass for efficient hydrolysis and biofuel production. Ind. Eng. Chem. Res. 2009, 48, 3713-3729. [CrossRef]

5. Cazacu, G.; Capraru, M.; Popa, V.I. Advances concerning lignin utilization in new materials. In Advances in Natural Polymers; Springer: Berlin, Germany, 2013; pp. 255-312.

6. Menon, V.; Rao, M. Trends in bioconversion of lignocellulose: Biofuels, platform chemicals \& biorefinery concept. Prog. Energy Combust. Sci. 2012, 38, 522-550. [CrossRef]

7. Taherzadeh, M.J.; Karimi, K. Pretreatment of lignocellulosic wastes to improve ethanol and biogas production: A review. Int. J. Mol. Sci. 2008, 9, 1621-1651. [CrossRef] [PubMed] 
8. Zakaria, M.R.; Hirata, S.; Hassan, M.A. Combined pretreatment using alkaline hydrothermal and ball milling to enhance enzymatic hydrolysis of oil palm mesocarp fiber. Bioresour. Technol. 2014, 169, 236-243. [CrossRef] [PubMed]

9. Kim, S.M.; Dien, B.S.; Tumbleson, M.E.; Rausch, K.D.; Singh, V. Improvement of sugar yields from corn stover using sequential hot water pretreatment and disk milling. Bioresour. Technol. 2016, 216, 706-713. [CrossRef] [PubMed]

10. Barakat, A.; Chuetor, S.; Monlau, F.; Solhy, A.; Rouau, X. Eco-friendly dry chemo-mechanical pretreatments of lignocellulosic biomass: Impact on energy and yield of the enzymatic hydrolysis. Appl. Energy 2014, 113, 97-105. [CrossRef]

11. Yuan, Z.; Long, J.; Wang, T.; Shu, R.; Zhang, Q.; Ma, L. Process intensification effect of ball milling on the hydrothermal pretreatment for corn straw enzymolysis. Energy Convers. Manag. 2015, 101, 481-488. [CrossRef]

12. Deng, A.; Ren, J.; Wang, W.; Li, H.; Lin, Q.; Yan, Y.; Sun, R.; Liu, G. Production of xylo-sugars from corncob by oxalic acid-assisted ball milling and microwave-induced hydrothermal treatments. Ind. Crops Prod. 2016, 79, 137-145. [CrossRef]

13. Huo, D.; Fang, G.; Yang, Q.; Han, S.; Deng, Y.; Shen, K.; Lin, Y. Enhancement of eucalypt chips' enzymolysis efficiency by a combination method of alkali impregnation and refining pretreatment. Bioresour. Technol. 2013, 150, 73-78. [CrossRef] [PubMed]

14. Da Silva, A.S.; Inoue, H.; Endo, T.; Yano, S.; Bon, E.P.S. Milling pretreatment of sugarcane bagasse and straw for enzymatic hydrolysis and ethanol fermentation. Bioresour. Technol. 2010, 101, 7402-7409. [CrossRef] [PubMed]

15. Inoue, H.; Yano, S.; Endo, T.; Sakaki, T.; Sawayama, S. Combining hot-compressed water and ball milling pretreatments to improve the efficiency of the enzymatic hydrolysis of eucalyptus. Biotechnol. Biofuels 2008, 1, 2. [CrossRef] [PubMed]

16. Lin, Z.; Huang, H.; Zhang, H.; Zhang, L.; Yan, L.; Chen, J. Ball milling pretreatment of corn stover for enhancing the efficiency of enzymatic hydrolysis. Appl. Biochem. Biotechnol. 2010, 162, 1872-1880. [CrossRef] [PubMed]

17. Silva, G.G.D.; Couturier, M.; Berrin, J.-G.; Buléon, A.; Rouau, X. Effects of grinding processes on enzymatic degradation of wheat straw. Bioresour. Technol. 2012, 103, 192-200. [CrossRef] [PubMed]

18. Lee, J.H.; Kwon, J.H.; Kim, T.H.; Choi, W. Impact of planetary ball mills on corn stover characteristics and enzymatic digestibility depending on grinding ball properties. Bioresour. Technol. 2017, 241, 1094-1100. [CrossRef] [PubMed]

19. Zhang, K.; Pei, Z.; Wang, D. Organic solvent pretreatment of lignocellulosic biomass for biofuels and biochemicals: A review. Bioresour. Technol. 2016, 199, 21-33. [CrossRef] [PubMed]

20. Pan, X.; Arato, C.; Gilkes, N.; Gregg, D.; Mabee, W.; Pye, K.; Xiao, Z.; Zhang, X.; Saddler, J. Biorefining of softwoods using ethanol organosolv pulping: Preliminary evaluation of process streams for manufacture of fuel-grade ethanol and co-products. Biotechnol. Bioeng. 2005, 90, 473-481. [CrossRef] [PubMed]

21. Zhao, X.; Cheng, K.; Liu, D. Organosolv pretreatment of lignocellulosic biomass for enzymatic hydrolysis. Appl. Microbiol. Biotechnol. 2009, 82, 815. [CrossRef] [PubMed]

22. Zakzeski, J.; Bruijnincx, P.C.A.; Jongerius, A.L.; Weckhuysen, B.M. The catalytic valorization of lignin for the production of renewable chemicals. Chem. Rev. 2010, 110, 3552-3599. [CrossRef] [PubMed]

23. De la Torre, M.; Moral, A.; Hernández, M.; Cabeza, E.; Tijero, A. Organosolv lignin for biofuel. Ind. Crops Prod. 2013, 45, 58-63. [CrossRef]

24. Chang, V.S.; Holtzapple, M.T. Fundamental factors affecting biomass enzymatic reactivity. In Twenty-first Symposium on Biotechnology for Fuels and Chemicals; Humana Press: Totowa, NJ, USA, 2000; pp. 5-37.

25. Lee, D.; Yu, A.H.C.; Saddler, J.N. Evaluation of cellulase recycling strategies for the hydrolysis of lignocellulosic substrates. Biotechnol. Bioeng. 1995, 45, 328-336. [CrossRef] [PubMed]

26. Öhgren, K.; Bura, R.; Saddler, J.; Zacchi, G. Effect of hemicellulose and lignin removal on enzymatic hydrolysis of steam pretreated corn stover. Bioresour. Technol. 2007, 98, 2503-2510. [CrossRef] [PubMed]

27. Zheng, Y.; Zhang, S.; Miao, S.; Su, Z.; Wang, P. Temperature sensitivity of cellulase adsorption on lignin and its impact on enzymatic hydrolysis of lignocellulosic biomass. J. Biotechnol. 2013, 166, 135-143. [CrossRef] [PubMed] 
28. Koo, B.-W.; Kim, H.-Y.; Park, N.; Lee, S.-M.; Yeo, H.; Choi, I.-G. Organosolv pretreatment of Liriodendron tulipifera and simultaneous saccharification and fermentation for bioethanol production. Biomass Bioenergy 2011, 35, 1833-1840. [CrossRef]

29. Barakat, A.; De Vries, H.; Rouau, X. Dry fractionation process as an important step in current and future lignocellulose biorefineries: A review. Bioresour. Technol. 2013, 134, 362-373. [CrossRef] [PubMed]

30. Mathew, A.K.; Chaney, K.; Crook, M.; Humphries, A.C. Alkaline pre-treatment of oilseed rape straw for bioethanol production: Evaluation of glucose yield and pre-treatment energy consumption. Bioresour. Technol. 2011, 102, 6547-6553. [CrossRef] [PubMed]

31. Lee, S.-H.; Teramoto, Y.; Endo, T. Enzymatic saccharification of woody biomass micro/nanofibrillated by continuous extrusion process I-Effect of additives with cellulose affinity. Bioresour. Technol. 2009, 100, 275-279. [CrossRef] [PubMed]

32. Hideno, A.; Inoue, H.; Tsukahara, K.; Fujimoto, S.; Minowa, T.; Inoue, S.; Endo, T.; Sawayama, S. Wet disk milling pretreatment without sulfuric acid for enzymatic hydrolysis of rice straw. Bioresour. Technol. 2009, 100, 2706-2711. [CrossRef] [PubMed]

33. Zhu, J.Y.; Pan, X.J. Woody biomass pretreatment for cellulosic ethanol production: Technology and energy consumption evaluation. Bioresour. Technol. 2010, 101, 4992-5002. [CrossRef] [PubMed]

34. Selig, M.; Weiss, N.; Ji, Y. Enzymatic Saccharification of Lignocellulosic Biomass: Laboratory Analytical Procedure; National Renewable Energy Laboratory: Golden, CO, USA, 2008.

35. Zhang, L.; Yan, L.; Wang, Z.; Laskar, D.D.; Swita, M.S.; Cort, J.R.; Yang, B. Characterization of lignin derived from water only and dilute acid flowthrough pretreatment of poplar wood at elevated tempeatures. Biotechnol. Biofuels 2015, 8, 203-217. [CrossRef] [PubMed]

36. Sluiter, A.; Hames, B.; Ruiz, R.; Scarlata, C.; Sluiter, J.; Templeton, D.; Crocker, D. Determination of Structural Carbohydrates and Lignin in Biomass: Laboratory Analytical Procedure; National Renewable Energy Laboratory: Golden, CO, USA, 2008.

37. Sluiter, A.; Hames, B.; Ruiz, R.; Scarlata, C.; Sluiter, J.; Templeton, D. Determination of Sugars, Byproducts, and Degradation Products in Liquid Fraction Process Samples: Laboratory Analytical Procedure; National Renewable Energy Laboratory: Golden, CO, USA, 2012.

38. Sluiter, A.; Hames, B.; Ruiz, R.; Scarlata, C.; Sluiter, J.; Templeton, D. Determination of Ash in Biomass: Laboratory Analytical Procedure; National Renewable Energy Laboratory: Golden, CO, USA, 2008.

39. El Hage, R.; Chrusciel, L.; Desharnais, L.; Brosse, N. Effect of autohydrolysis of Miscanthus $x$ giganteus on lignin structure and organosolv delignification. Bioresour. Technol. 2010, 101, 9321-9329. [CrossRef] [PubMed]

40. Huijgen, W.J.J.; Smit, A.T.; De Wild, P.J.; Den Uil, H. Fractionation of wheat straw by prehydrolysis, organosolv delignification and enzymatic hydrolysis for production of sugars and lignin. Bioresour. Technol. 2012, 114, 389-398. [CrossRef] [PubMed]

41. Jeffries, T.W. Biodegradation of lignin-carbohydrate complexes. In Physiology of Biodegradative Microorganisms; Springer: Dordrecht, The Netherlands, 1991; pp. 163-176.

42. Zadeh, E.M.; O'Keefe, S.F.; Kim, Y.-T. Utilization of lignin in biopolymeric packaging films. ACS Omega 2018, 3, 7388-7398. [CrossRef]

(C) 2018 by the authors. Licensee MDPI, Basel, Switzerland. This article is an open access article distributed under the terms and conditions of the Creative Commons Attribution (CC BY) license (http://creativecommons.org/licenses/by/4.0/). 